\title{
Identification and Prioritization of Factors Affecting Neuromarketing in Sport Based on Analytical Hierarchy Process (AHP)
}

\author{
Kazem Danesh Sani ${ }^{1}$, Ali Mohammad Safania ${ }^{*}$, Hossein Poursoltani ${ }^{2}$ \\ ${ }^{1}$ Science and Research Branch, Islamic Azad University, Tehran, Iran \\ ${ }^{2}$ Department of Physical Education, Payame Noor University, Tehran, Iran
}

\section{Article Info:}

\section{ABSTRACT}

Introduction: Using analytical hierarchy process (AHP), the aim of this study was to identify and prioritize the factors affecting neuromarketing in sports. Materials and Methods: Societies and statistical samples in qualitative section were including 9 doctors of neurologists and neuroscience professionals and 8 marketers and experts in the field of marketing and neuromarketing. To this end, by preparing the couple scale questionnaires using AHP and confirm its validity by six experts, weighting and ranking of different factors were analyzed by the Expert choice software. Results: Software output analysis revealed that stimulation of the consumer feeling using their five senses (with weight of 0.303 ) is the most important factor that influence neuromarketing in sports followed by metaphor and memories associative as the second crucial factor. In addition, quality with grade importance was the most important factor in attracting trust component. Conclusion: Identify and prioritize the factors affecting neuromarketing can help the managers and sport marketers to know how human brain reacted to the messages designed by the sport advertising and the methods that increase the likelihood of consumer to purchase sport products. In addition, neuromarketing could be helpful to decrease costs of advertisements in sport.

Key words:

1. Neurosciences

2. Neuroimaging

3. Brain

4. Sports

*Corresponding Author: Ali Mohammad Safania

E-mail:A.M.Safania@Gmail.Com 


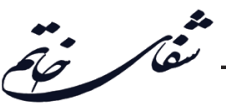

شناسايى و اولويتبندى عوامل مؤثر بر بازاريابى عصبى در ورزش بر اساس فرايند تحليل سلسله مراتبى (AHP)

\author{
كاظم دانش ثانى'، على محمد صفانيا'،: حسين يورسلطانى' \\ 'واحد علوم و تحقيقات، دانشكاه آزاد اسلامى، تهران، ايران \\ rكروه تربيت بدنى، دانشخاه بيام نور، تهران، ايران
}

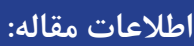

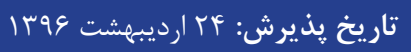

اصلاحيه: 19 فروردين و9بات

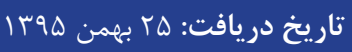

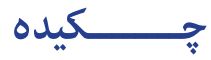

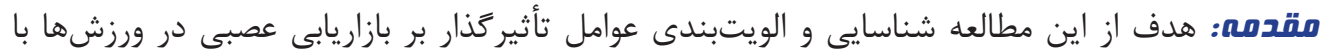

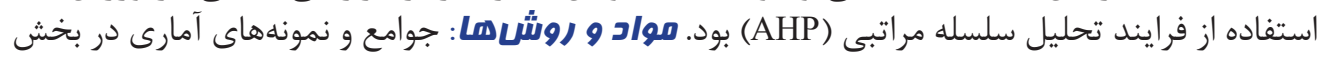

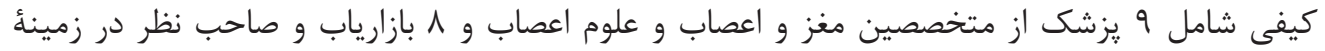

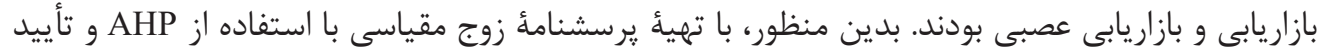

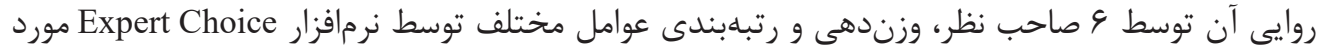

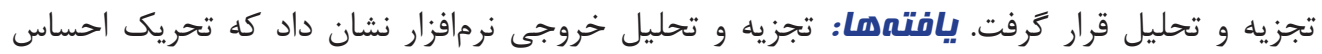

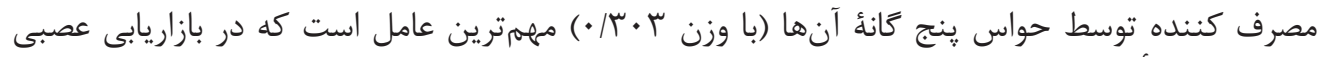

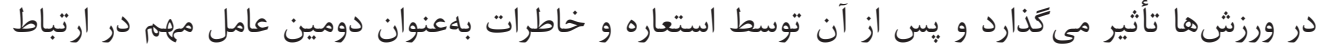

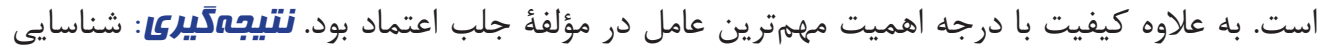

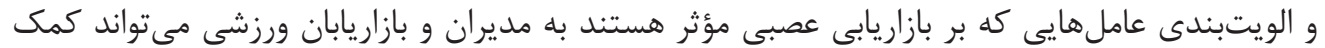

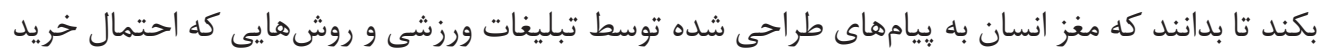

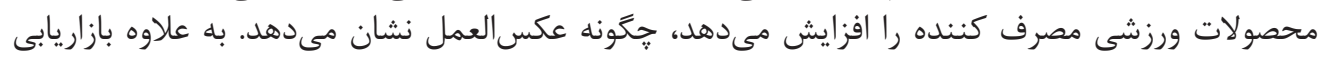

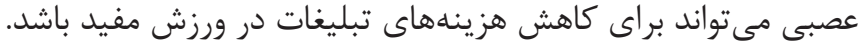




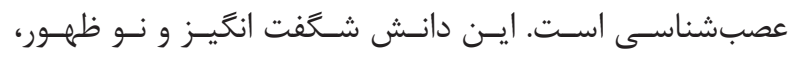

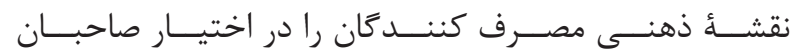

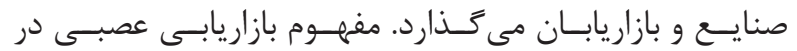

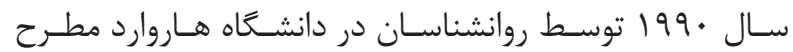

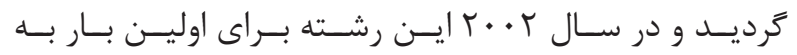

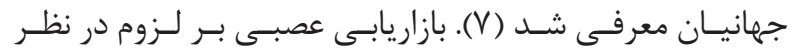

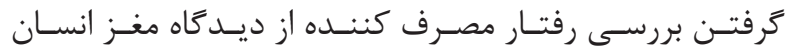

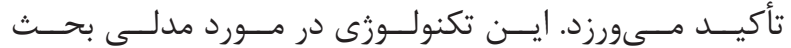

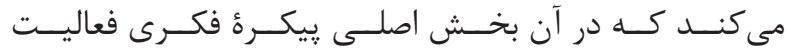

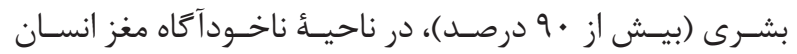

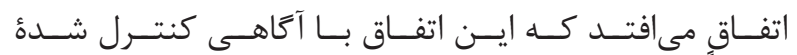

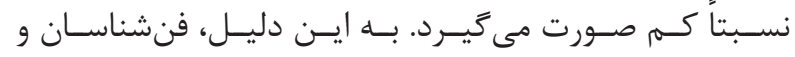

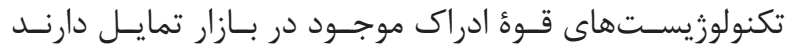

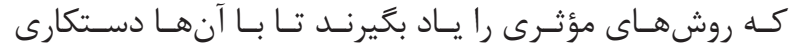

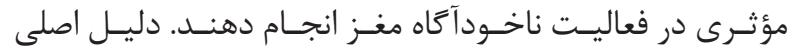

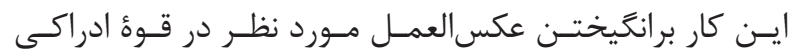

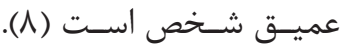

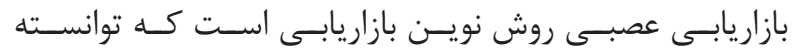

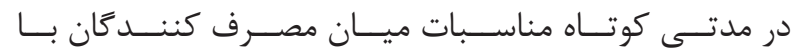

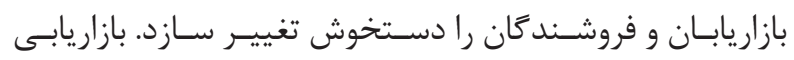

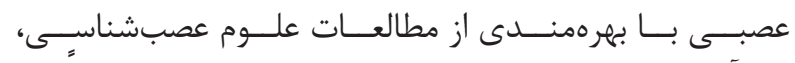

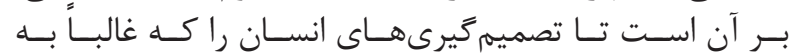

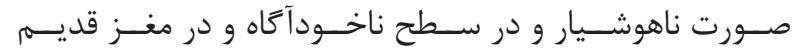

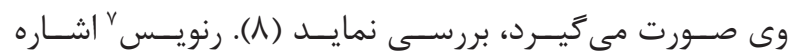

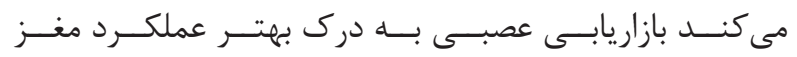

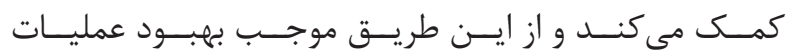

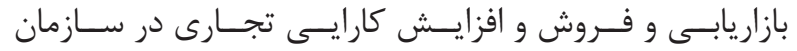

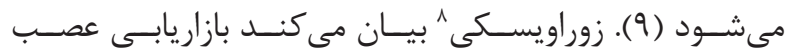

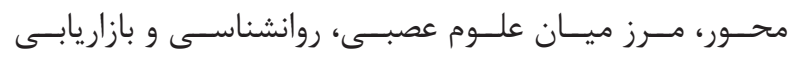

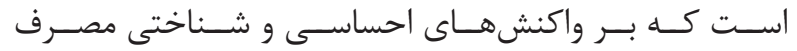

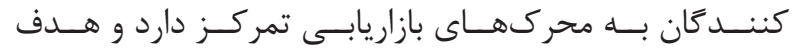

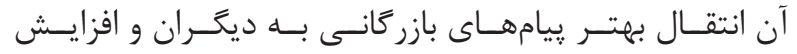

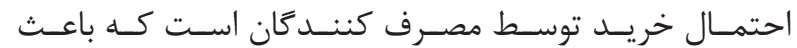

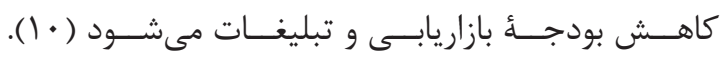

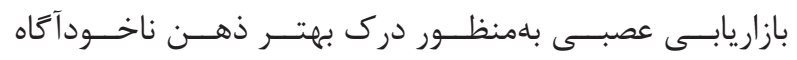

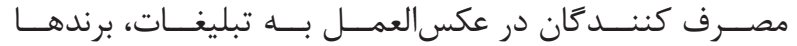

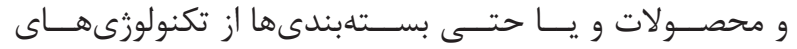

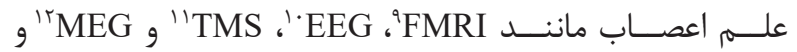

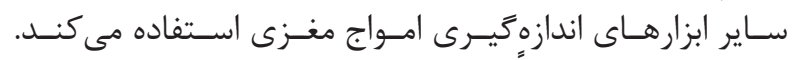

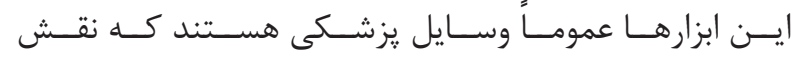

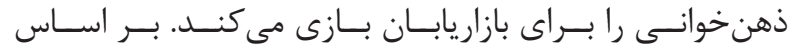

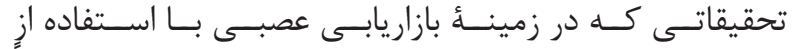

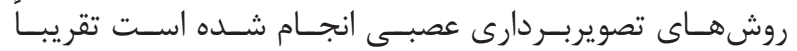

\section{${ }^{1}$ Neuroscience}

${ }^{2}$ Morin

${ }^{3}$ Northwestern university

${ }^{4}$ Lima Cruz

${ }^{5}$ Karmarkar

${ }^{6}$ Neuromarketing

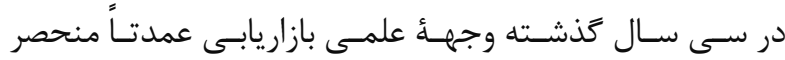

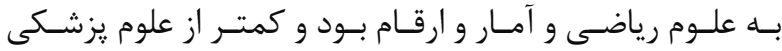

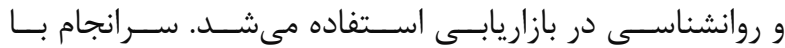

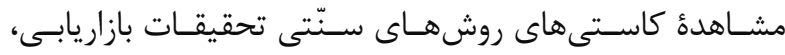

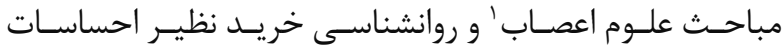

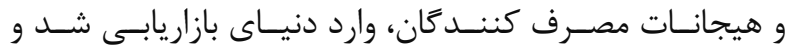

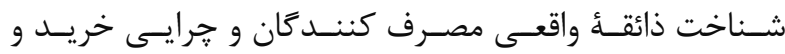

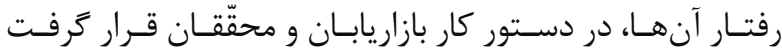

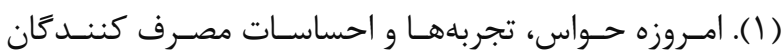

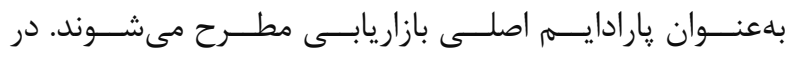

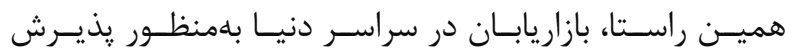

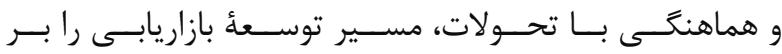

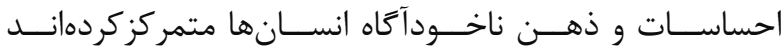

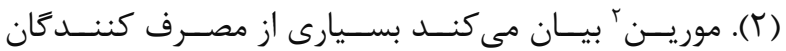

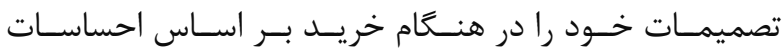

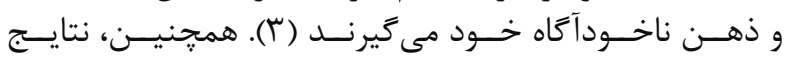

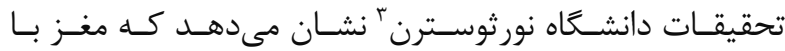

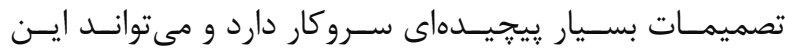

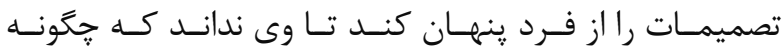

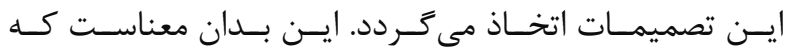

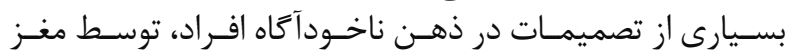

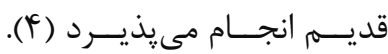

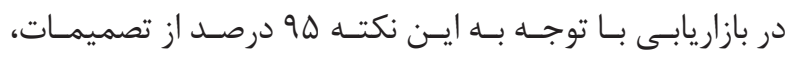

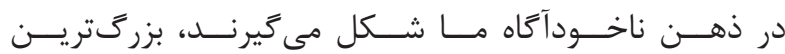

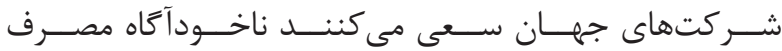

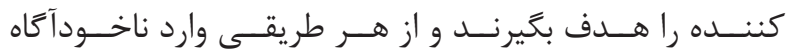

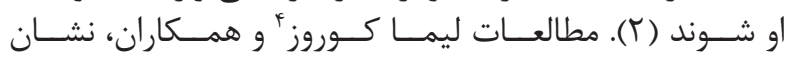

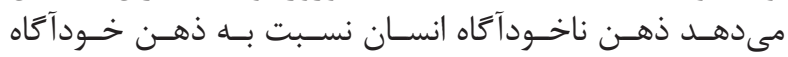

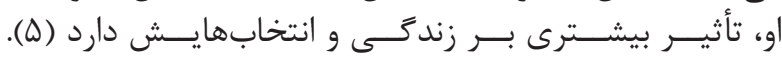

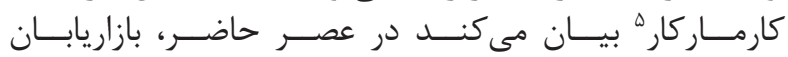

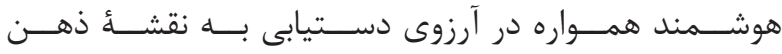

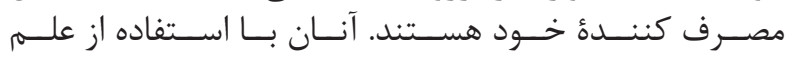

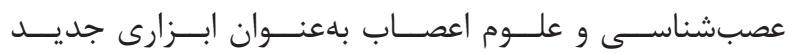

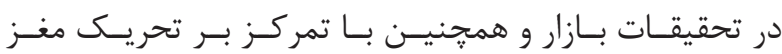

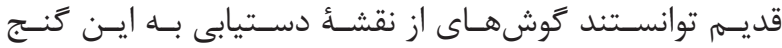

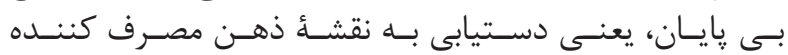

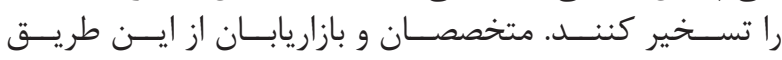

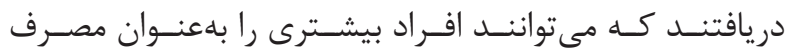

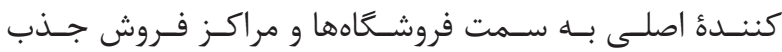

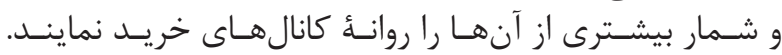

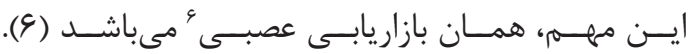

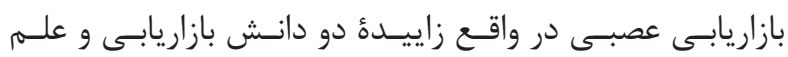

\footnotetext{
${ }^{7}$ Renvoise

${ }^{8}$ Zurawicki

${ }^{9}$ Functional magnetic resonance imaging

${ }^{10}$ Electroencephalography

${ }^{11}$ Transcranial magnetic stimulation

${ }^{12}$ Magnetoencephalography
} 


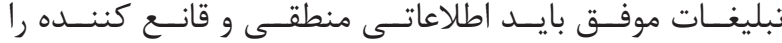

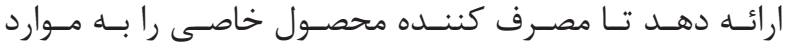

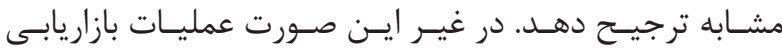

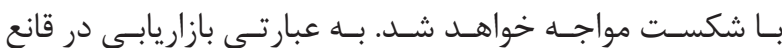

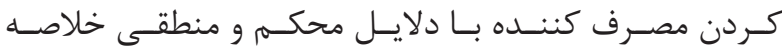

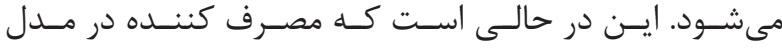

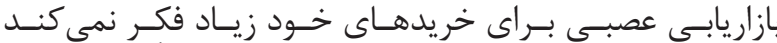

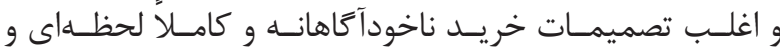

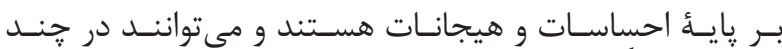

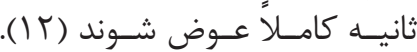

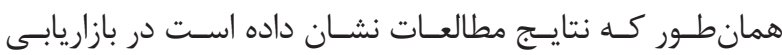

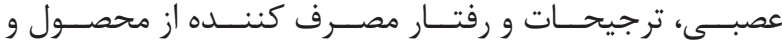

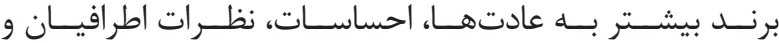

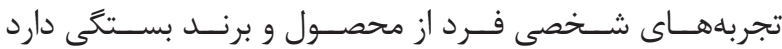

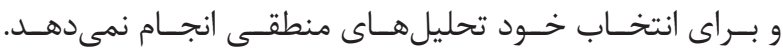

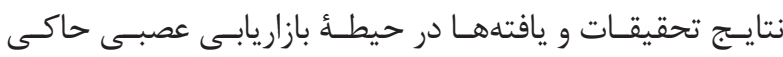

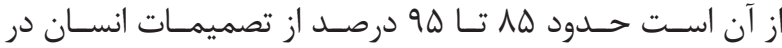

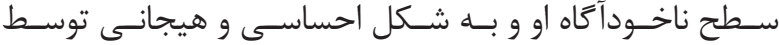

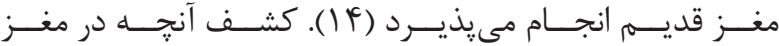

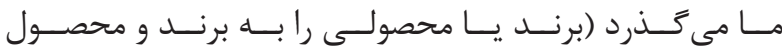

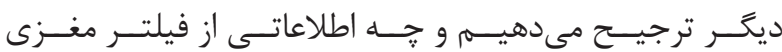

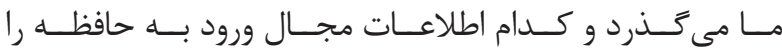

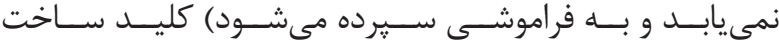

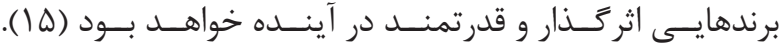

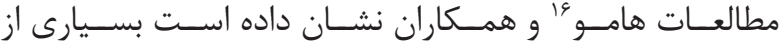

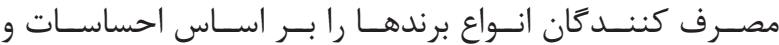

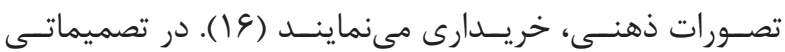

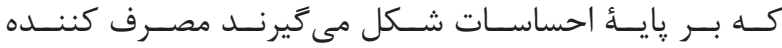

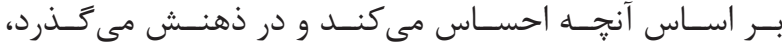

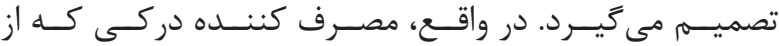

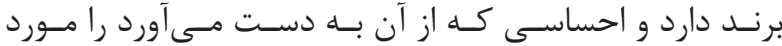

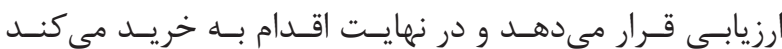

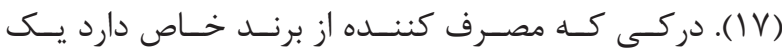

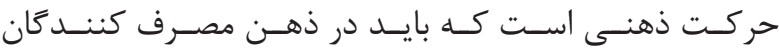

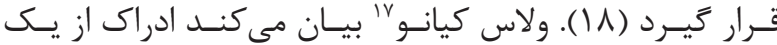

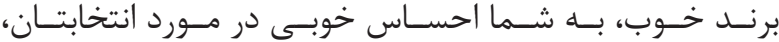

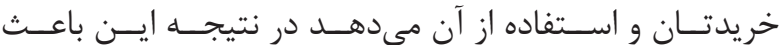

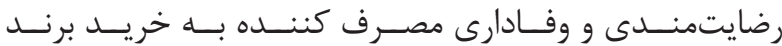

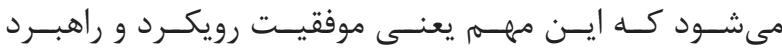

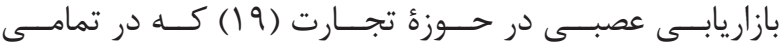

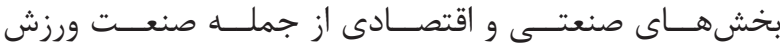

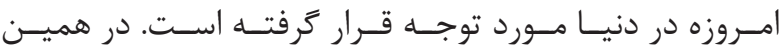

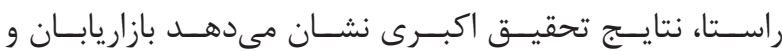

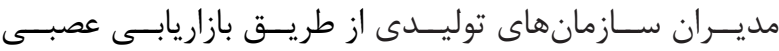

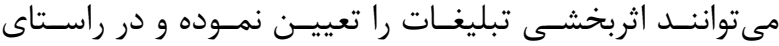

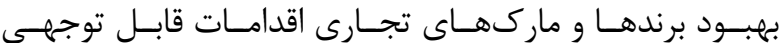

${ }^{13}$ Krajnovic

${ }^{14}$ Venkatraman

${ }^{15}$ Grabner and Huber
در بيشـتر ايــن بررســىها از تكنولوزىهــاى FMRI و EEG

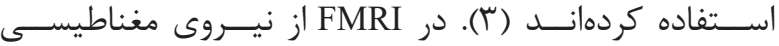

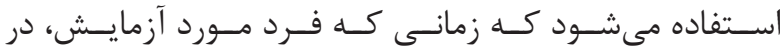

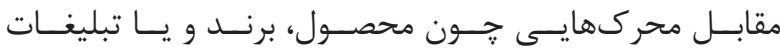

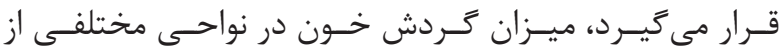

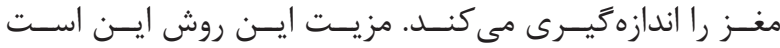

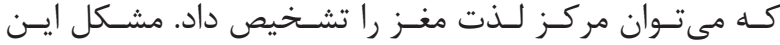

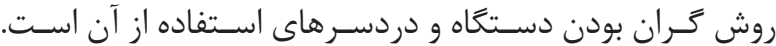

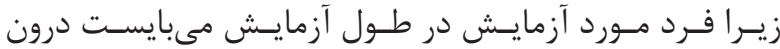

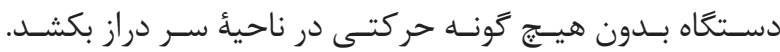

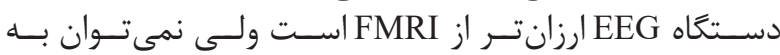

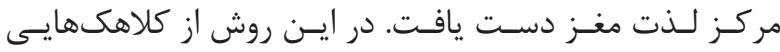

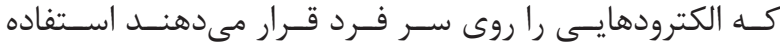

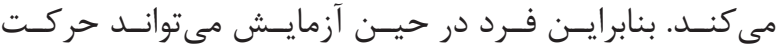

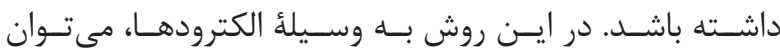

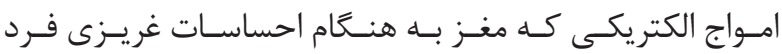

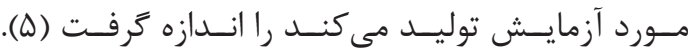

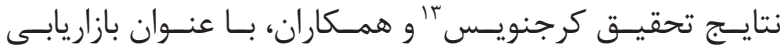

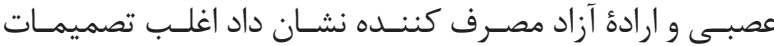

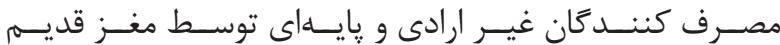

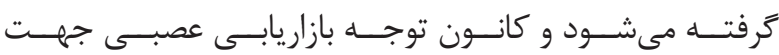

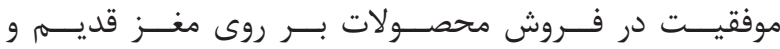

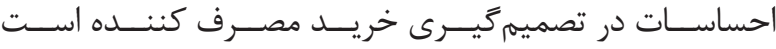

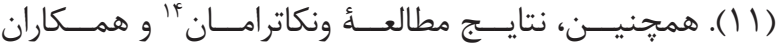

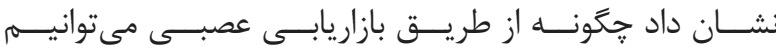

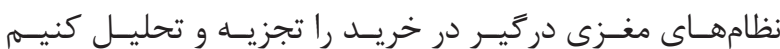

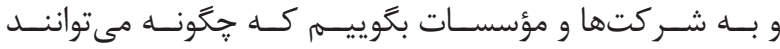

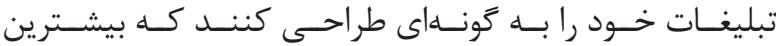

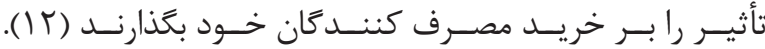

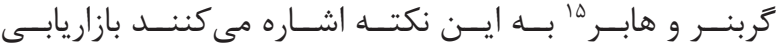

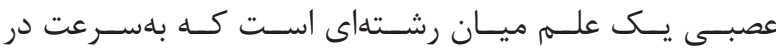

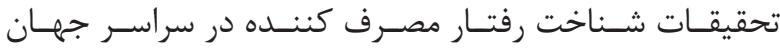

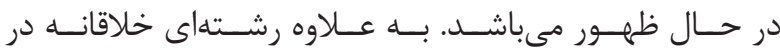

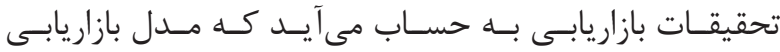

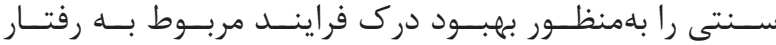

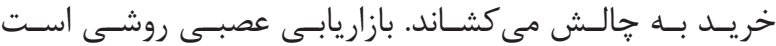

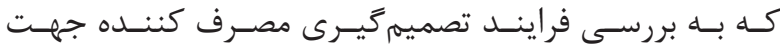

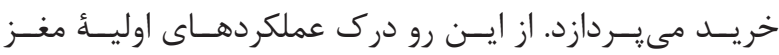

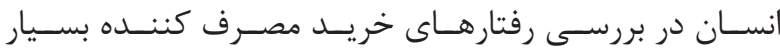

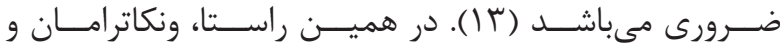

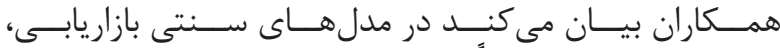

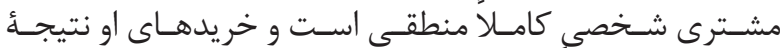

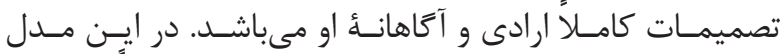

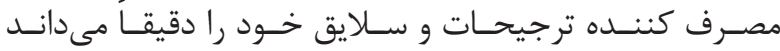

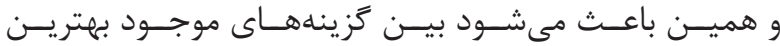

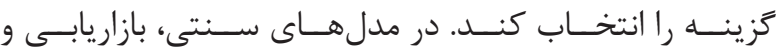

${ }^{16} \mathrm{Hammou}$

${ }^{17}$ Vlasceanu 
صـورت ميدانسى بــه اجـرا درآمـده اسـت.

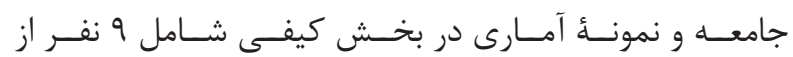

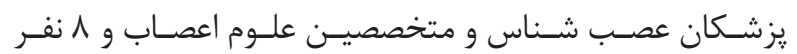

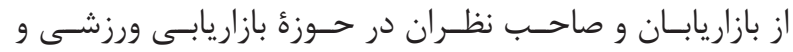

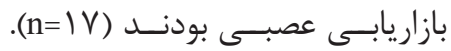

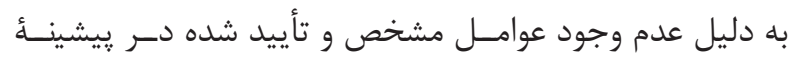

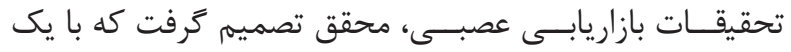

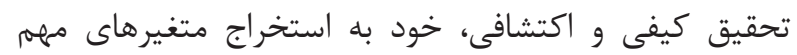

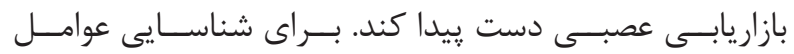

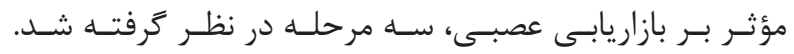

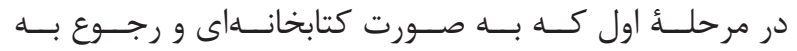

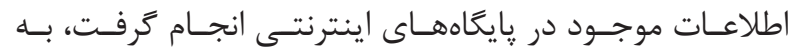

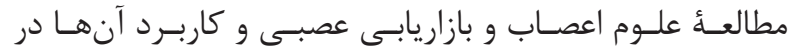

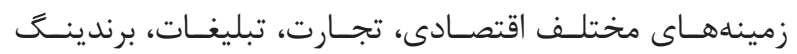

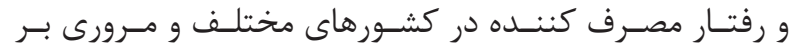

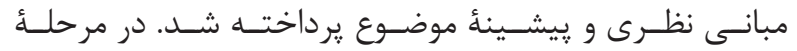

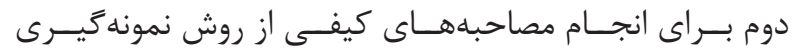

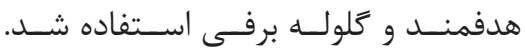

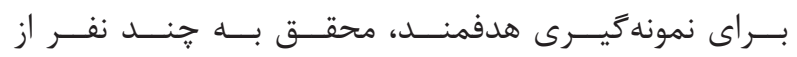

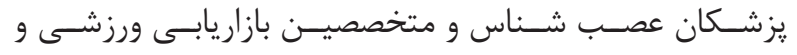

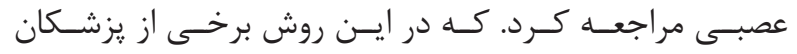

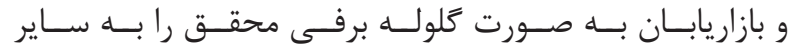

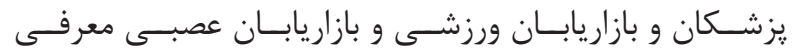

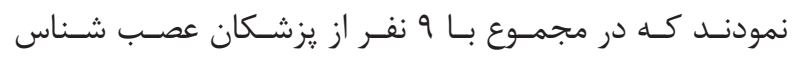

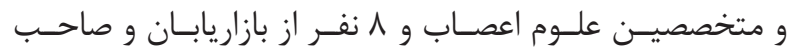

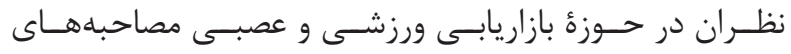

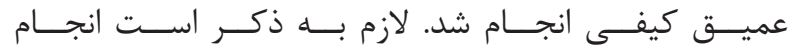

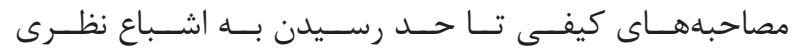

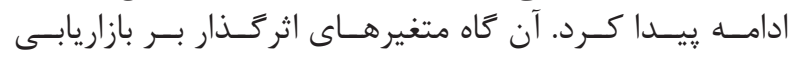

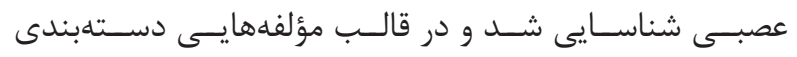

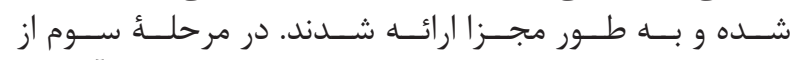

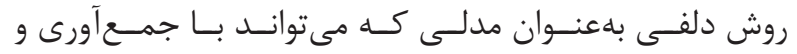

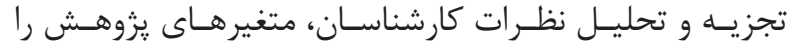

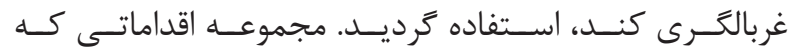

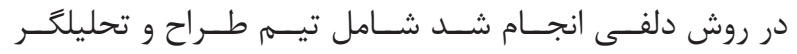

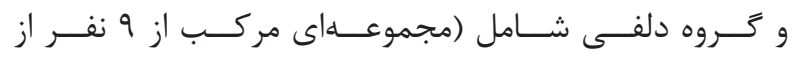

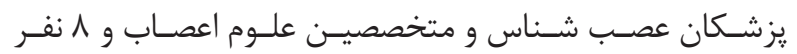

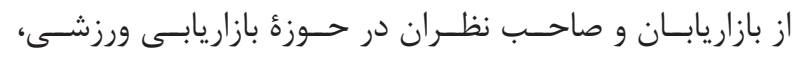

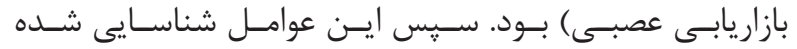

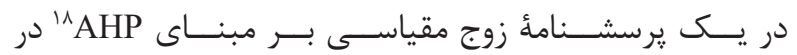

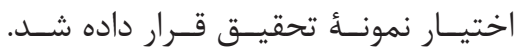

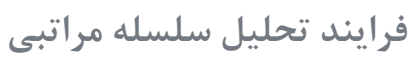

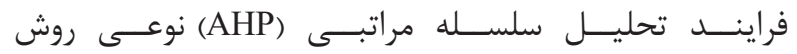

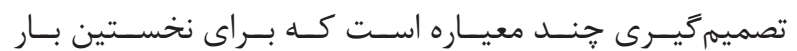

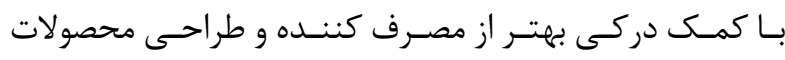

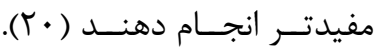

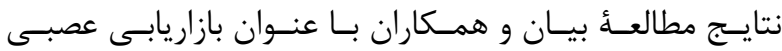

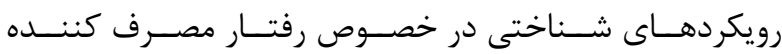

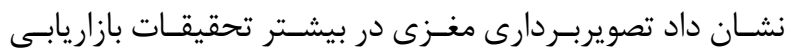

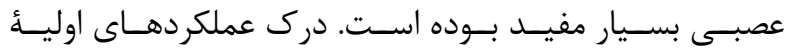

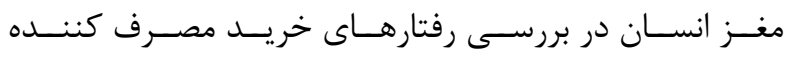

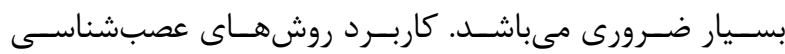

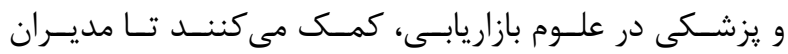

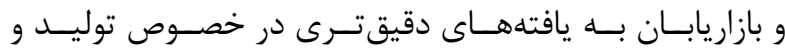

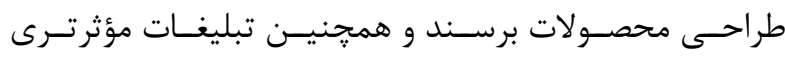

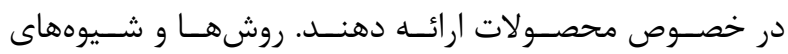

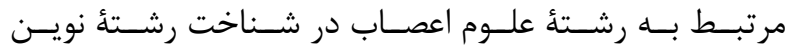

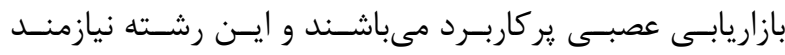

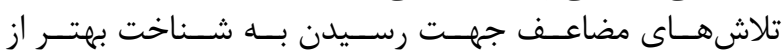

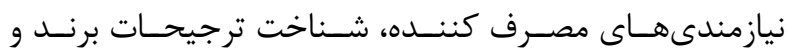

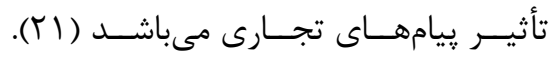

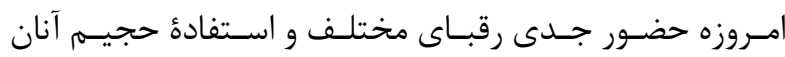

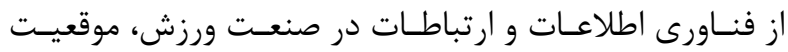

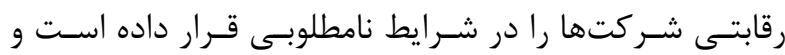

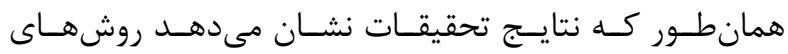

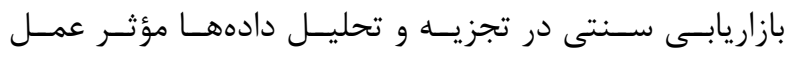

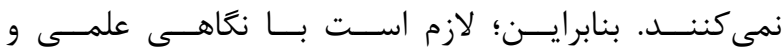

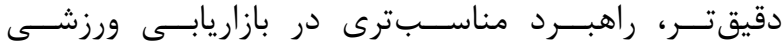

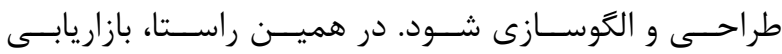

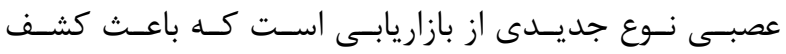

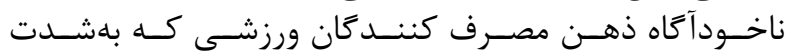

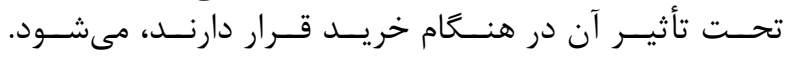

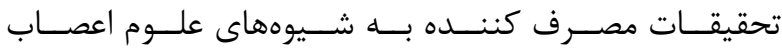

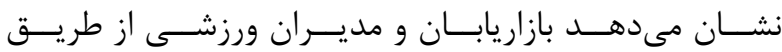

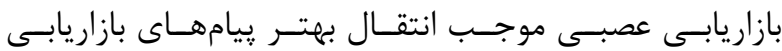

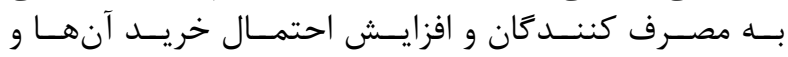

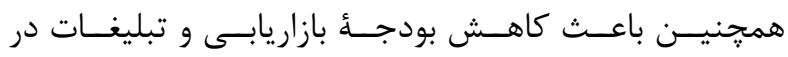

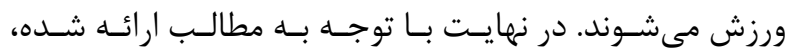

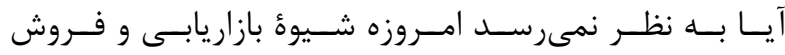

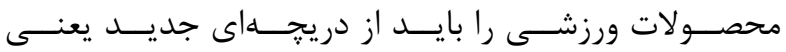

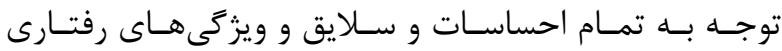

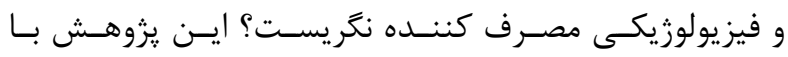

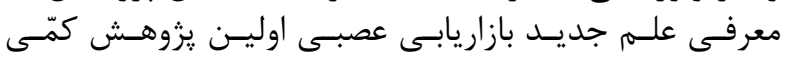

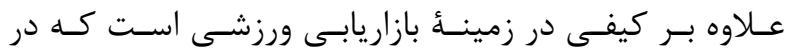

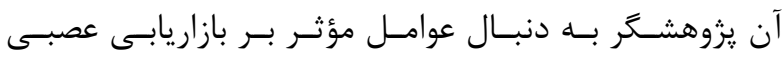

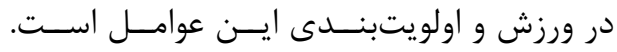

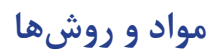

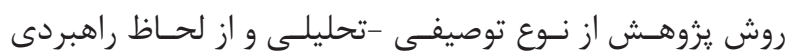

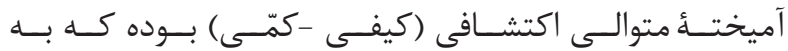

${ }^{18}$ Analytical hierarchy process 


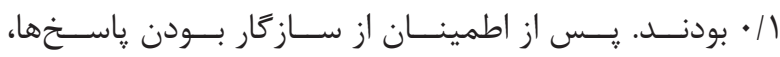

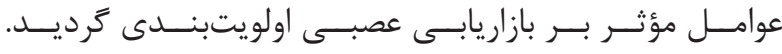

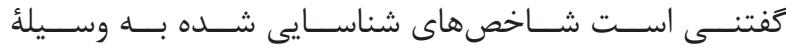

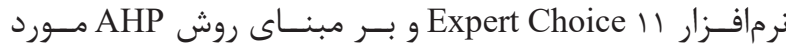

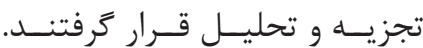

بافتهها

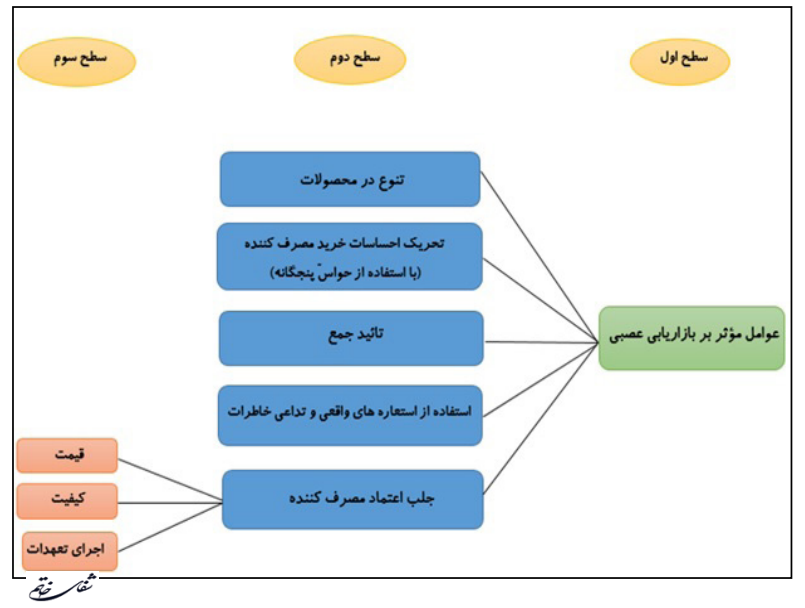

تصوير ا- درخت سلسله مراتب عوامل مؤثر بر بازاريابى عصبى در ورزش.

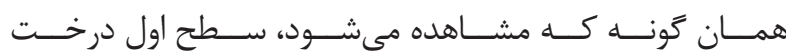

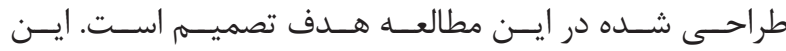

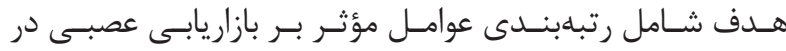

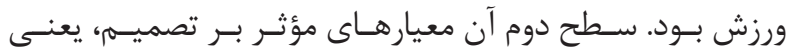

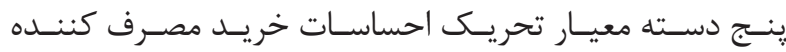

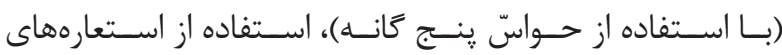

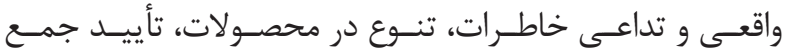

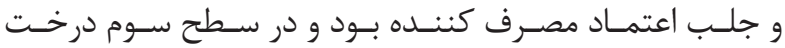

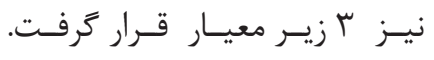

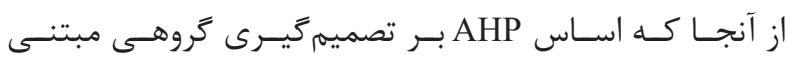

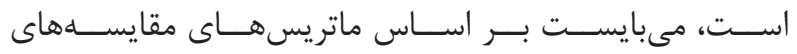

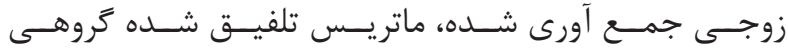

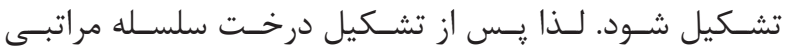

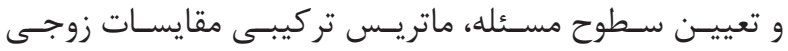

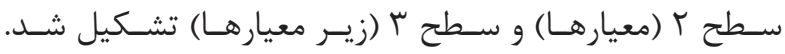

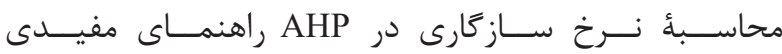

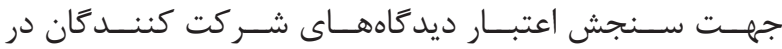

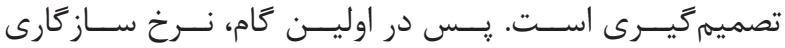
(CR)

جدول ا- نرخ سازكًارى ماتريس تركيبى مقايسات زوجى معيارها و زير معيارها.

\begin{tabular}{|c|c|}
\hline CR & 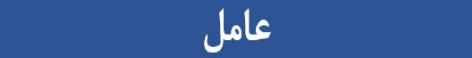 \\
\hline$\cdot 1 \cdot \Delta$ & سطح Y (معيارها) \\
\hline $.1 \cdot 1$ & سطح ب (زير معيارهاي جلب اعتماد مصرف كنيده) \\
\hline
\end{tabular}

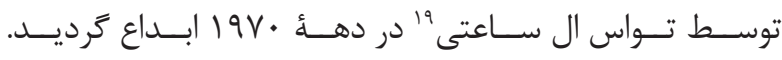

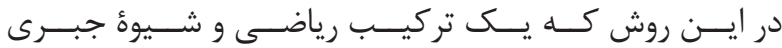

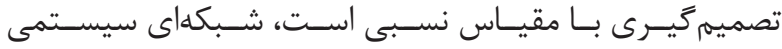

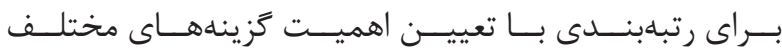

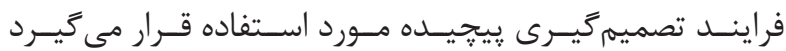

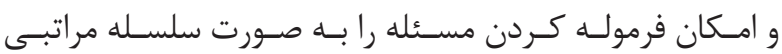

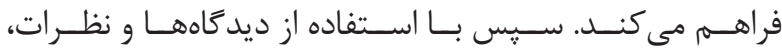

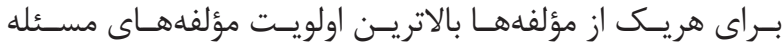

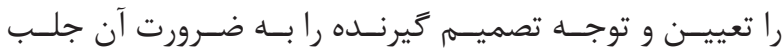

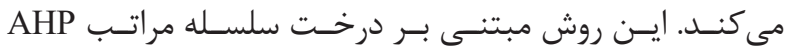

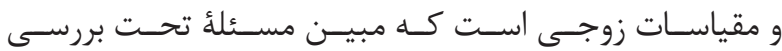

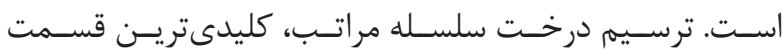

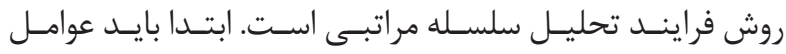

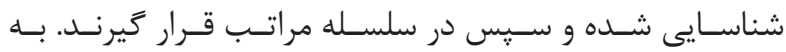

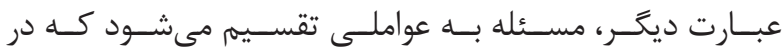

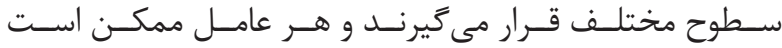

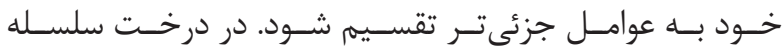

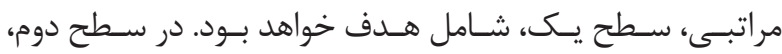

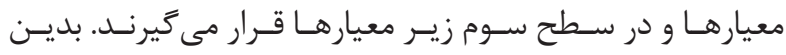

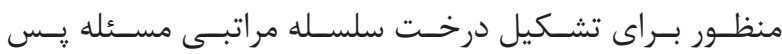

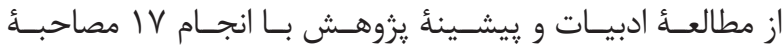

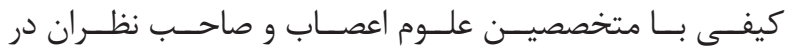

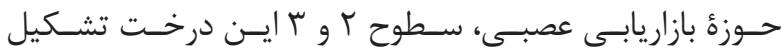

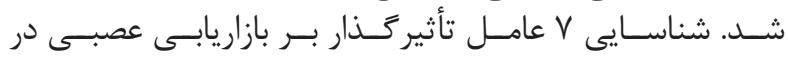

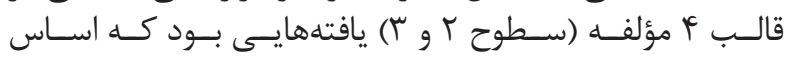

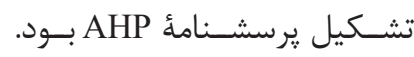

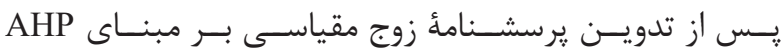

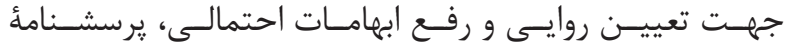

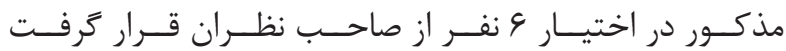

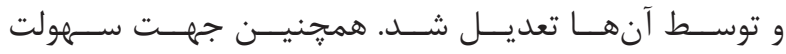

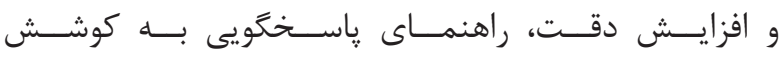

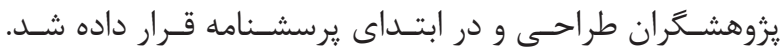

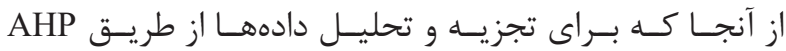

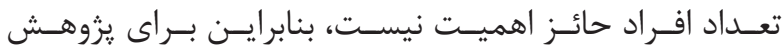

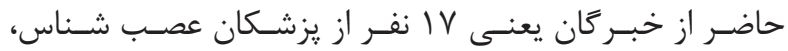

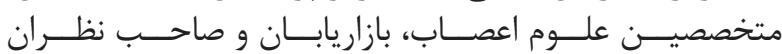

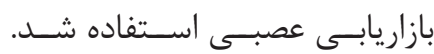

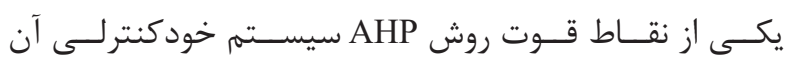

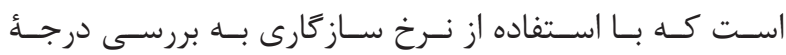

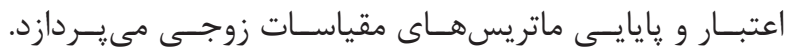

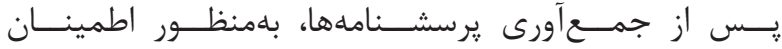

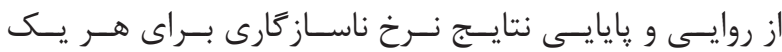

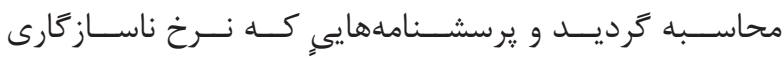

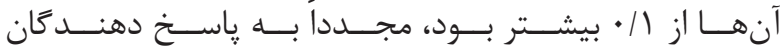

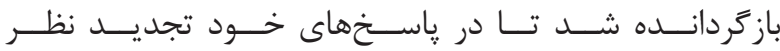

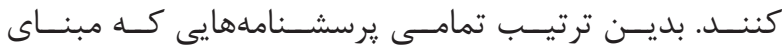

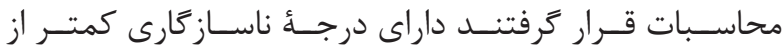




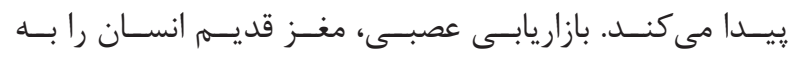

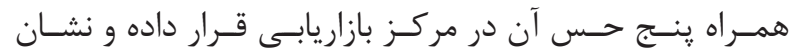

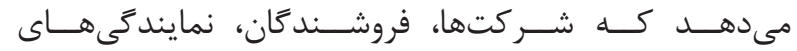

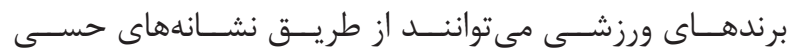

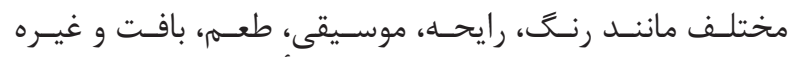

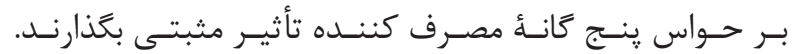

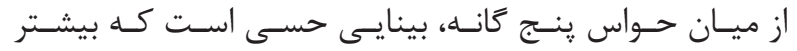

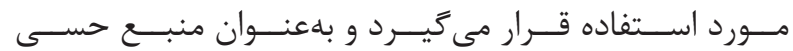

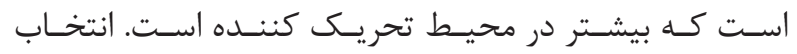

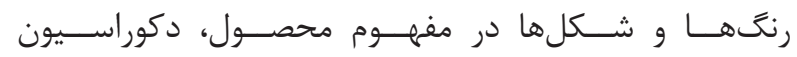

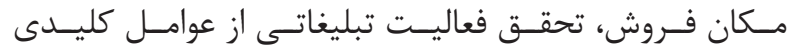

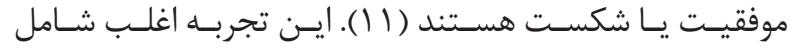

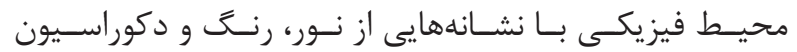

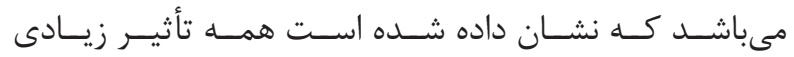

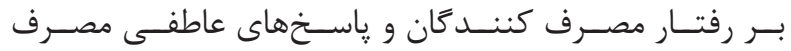

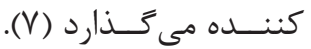

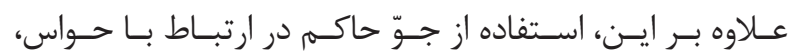

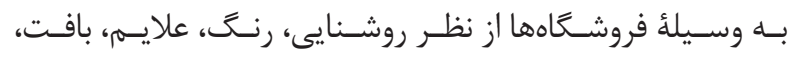

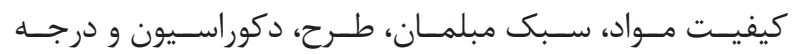

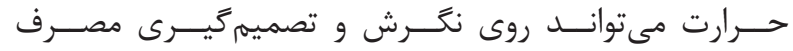

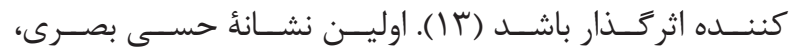

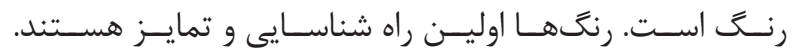

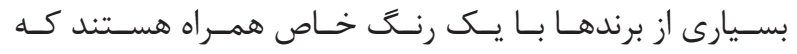

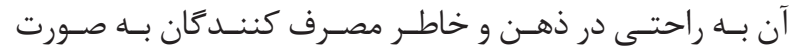

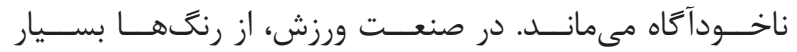

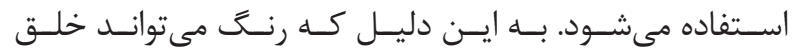

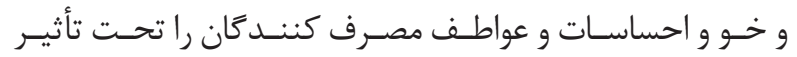

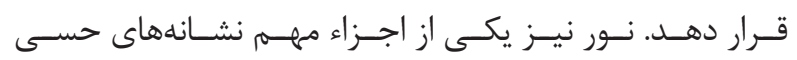

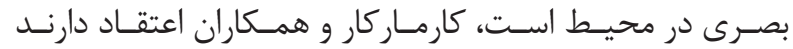

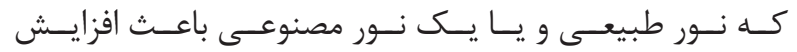

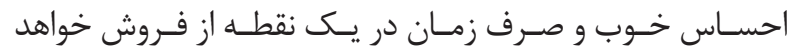

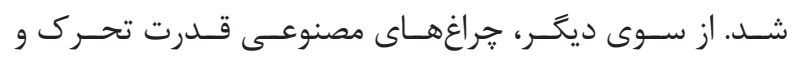

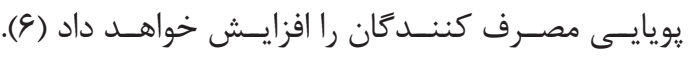

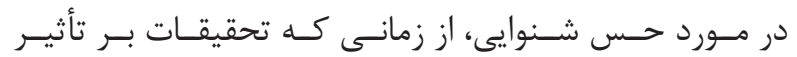

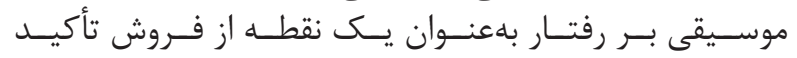

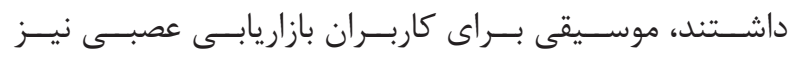

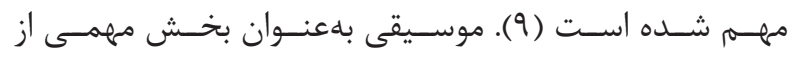

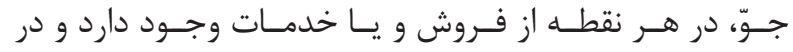

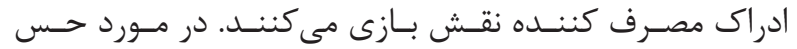

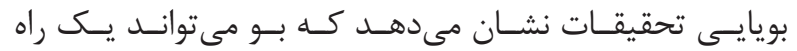

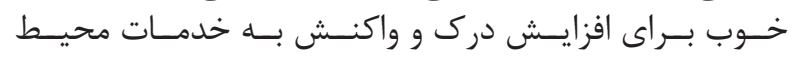

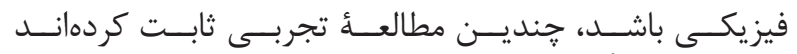

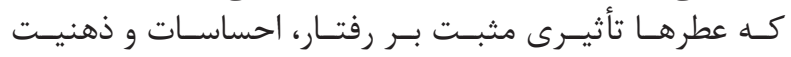

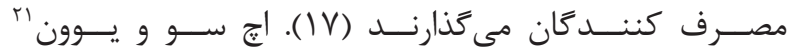

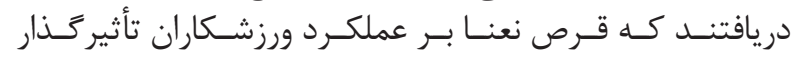

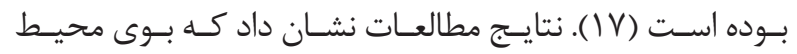

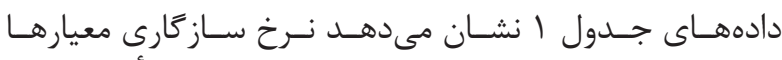

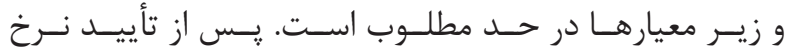

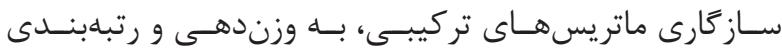

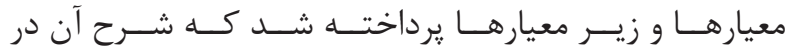

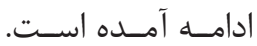

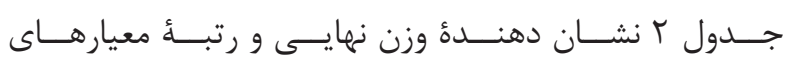

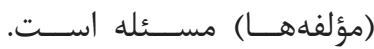
جدول r- وزن و رتبهُ معيارها (سطح دوم).

\begin{tabular}{|c|c|c|}
\hline رتبه & وزن نهايى & معيار \\
\hline 1 & $\cdot / L \cdot r F$ & تحريك احساسات \\
\hline$r$ & $\cdot / T \Delta \& K$ & تأييد جمع \\
\hline$\Delta$ & - /NAFD & تنوع در محصولات \\
\hline t & - TARA & استفاده از استعارهها \\
\hline f & - ITTRD & جلب اعتماد مصرف كنـنده \\
\hline
\end{tabular}

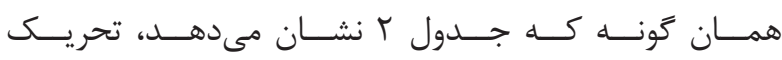

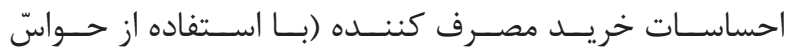

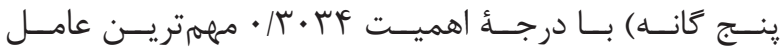

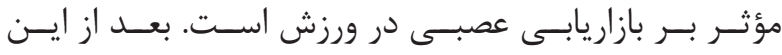

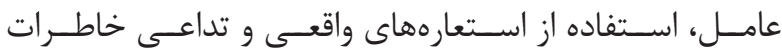

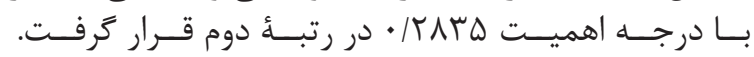
جـدول ب خروجسى نرمافزار

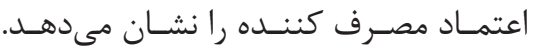

جدول r - وزن و رتبهُ زير معيارهاى مؤلفه جلب اعتماد مصرف كننده.

\begin{tabular}{|c|c|c|}
\hline رتبه & وزن نهايى & زير معيار (كويه) \\
\hline$r$ &.$/ 19 人 \vee$ & قيمت \\
\hline 1 & ./ & كيفيت \\
\hline$r$ & . /trAG & اجراى تعهمدات \\
\hline
\end{tabular}

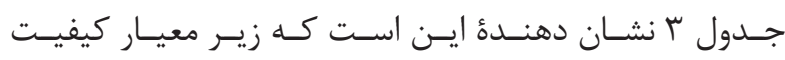

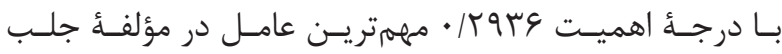

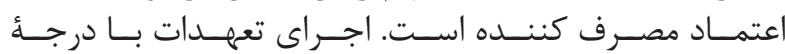

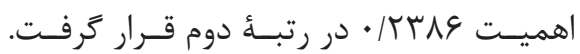

بحث و نتيجه كيرى

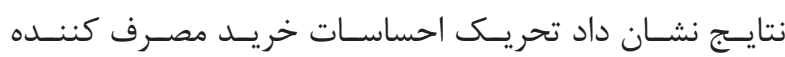

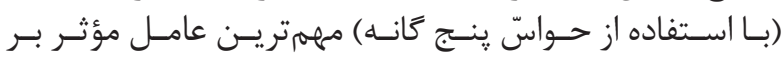

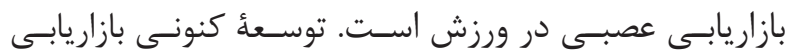

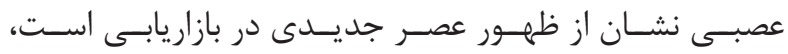

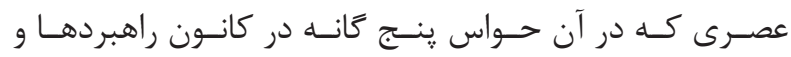

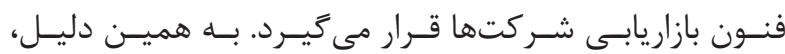

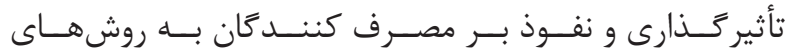

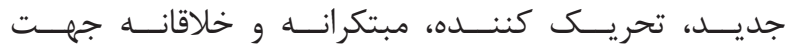

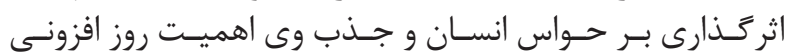

${ }^{21} \mathrm{Hsu}$ and Yoon 


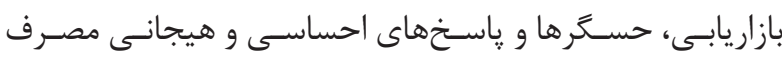

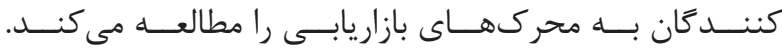

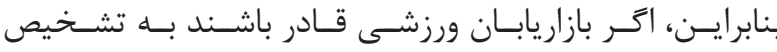

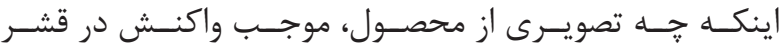

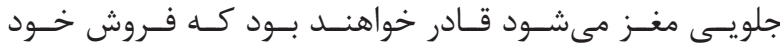

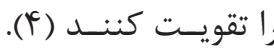

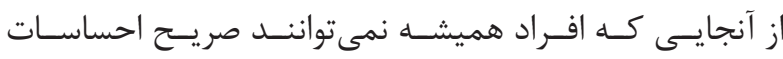

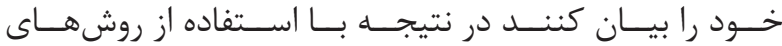

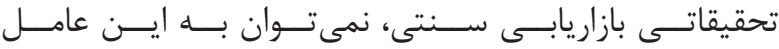

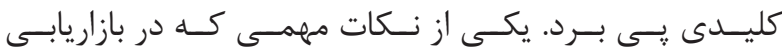

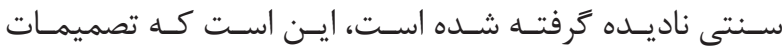

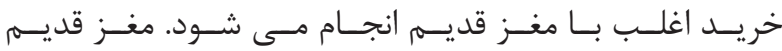

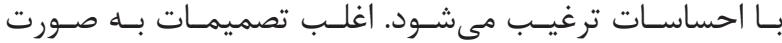

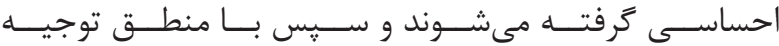

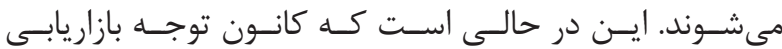

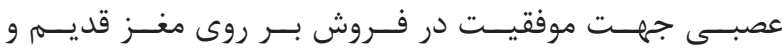

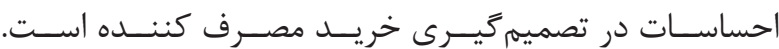

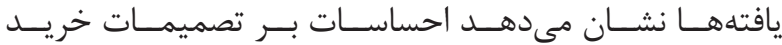

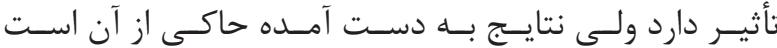

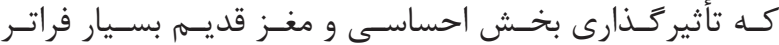

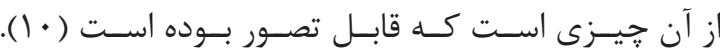

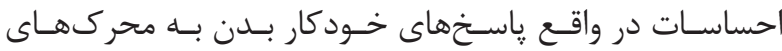

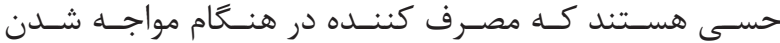

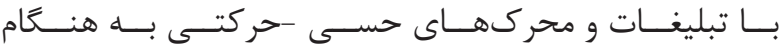

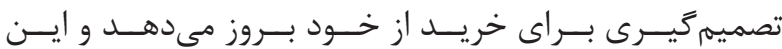

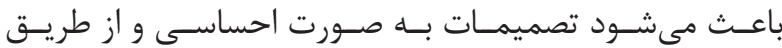

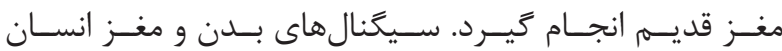

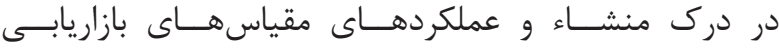

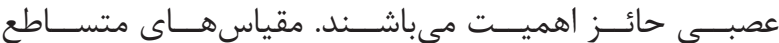

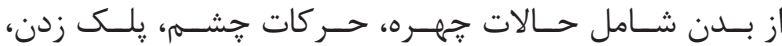

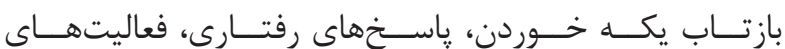

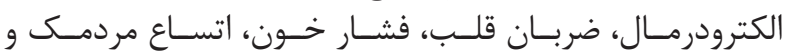

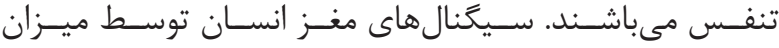

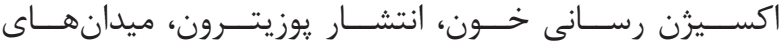

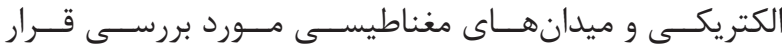

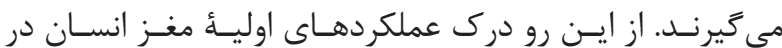

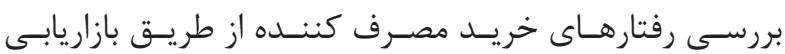

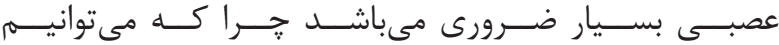

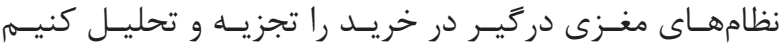

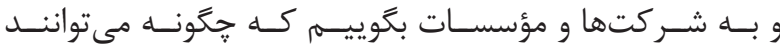

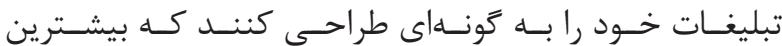

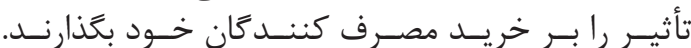

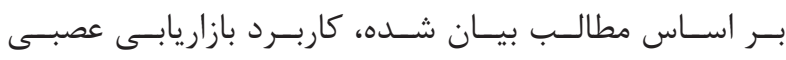

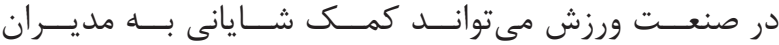

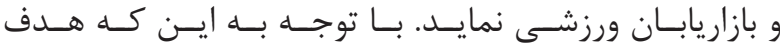

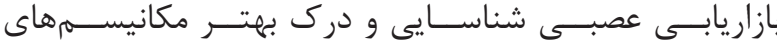

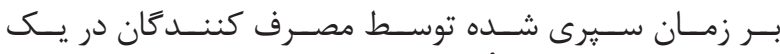

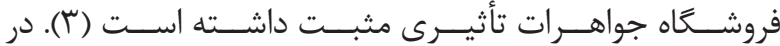

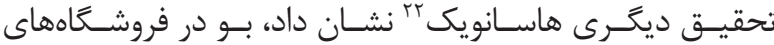

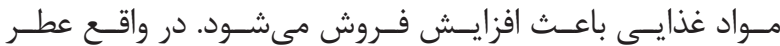

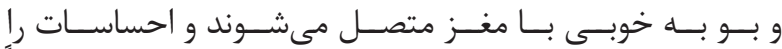

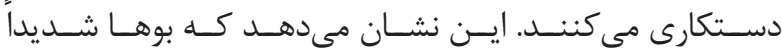
بــاعواطـف و احساســات در ارتبــاط هســتـند (9 (1).

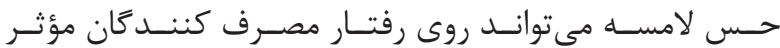

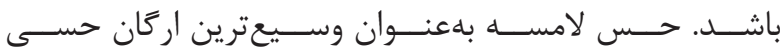

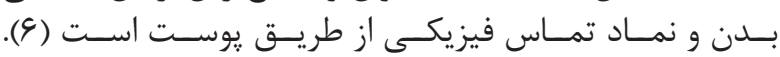

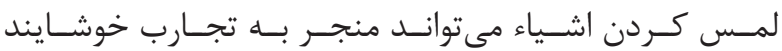

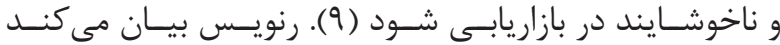

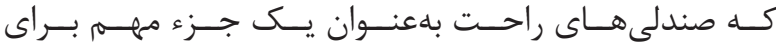

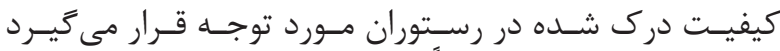

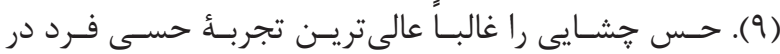

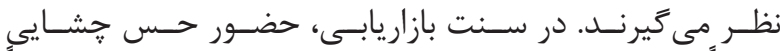

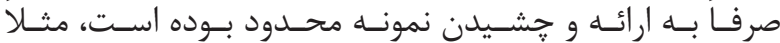

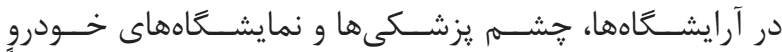

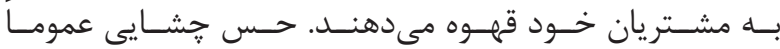

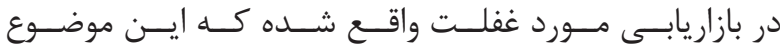

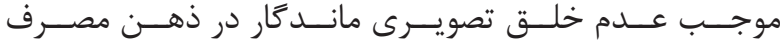

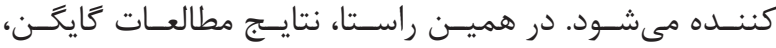

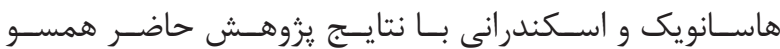

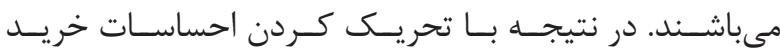

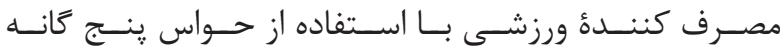

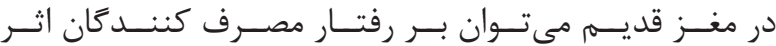

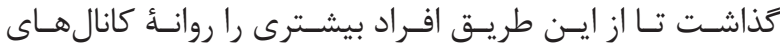

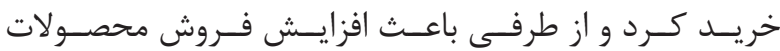

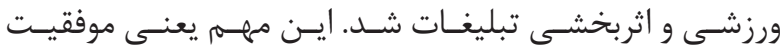

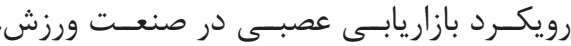

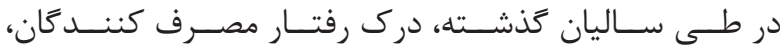

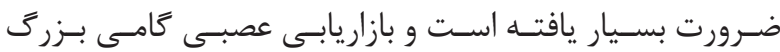

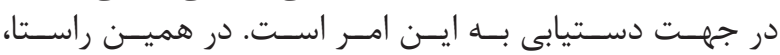

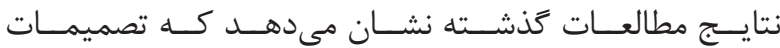

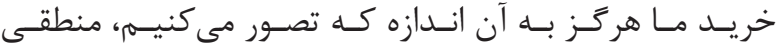

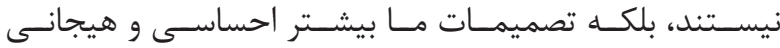

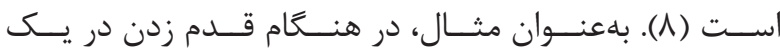
نمايند

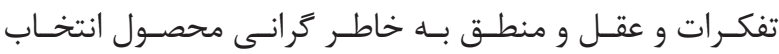

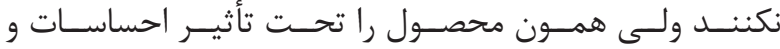

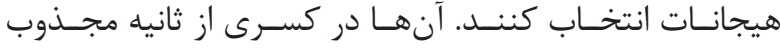

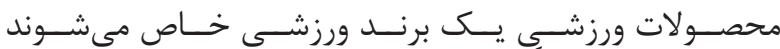

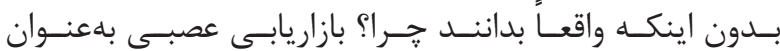

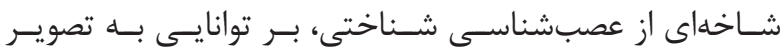

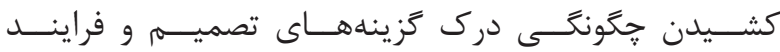

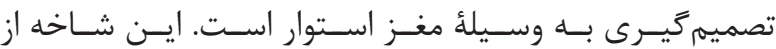




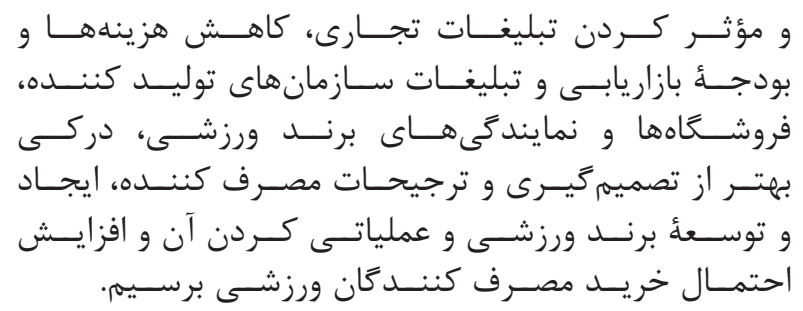

1. Yoon C, Gonzalez R, Bechara A, Berns G, Dagher $\mathrm{A}$, Dube L, et al. Decision neuroscience and consumer decision making. Market Lett. 2012; 23(2): 473-85.

2. Achrol RS, Kotler P. Frontiers of the marketing paradigm in the third millennium. Journal of the Academy of Marketing Science. 2012; 40(1): 52-35.

3. Morin C. Neuromarketing: the new science of consumer behavior. Society. 2011;48(2): 131-5.

4. Klincekova S. Neuromarketing - research and prediction of the future. International Journal of Management Science and Business Administration. 2016; 2: 53-7.

5. Lima Cruz CM, Medeiros JF, Hermes LC, Marcon A, Marcon E. Neuromarketing and the advances in the consumer behavior studies: a systematic review of the literature". Int. J. Business and Globalisation. 2016; 17 (3): $145-53$.

6. Karmarkar UR, Shiv B, Knutson B. Cost conscious? the neural and behavioral impact of price primacy on decision-making. Journal of Marketing Research. 2015; 56(4): 467-81.

7. Ariely D, Berns GS. Neuromarketing: the hope and hype of neuroimaging in business. Nat Rev Neurosci. 2010; 11(4): 284-92.

8. Bakardjieva E, Allan JK. Neuromarketing research practices: attitudes, ethics, and behavioral intentions. Ethics \& Behavior. 2017; 27(3): 179-200.

9. Renvoise P, Morin C. Neuromarketing: understanding the buy buttons in your customer's brain. Thomas Nelson Inc. 2007; 12: 51-6.

10. Zurawicki L. Neuromarketing: exploring the brain of the consumer. University of Massachusetts Boston. London: New York. 2011. p. 287-288.

11. krajnovic a, sikiric d, jasic d. Neuromarketing and customers' free. $13^{\text {th }}$ international conference. budapest. 2012.

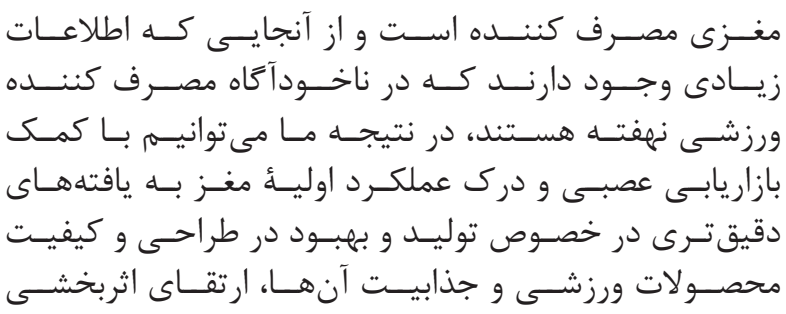

منابع

12. Venkatraman V, Dimoka A, Paviou PA, Hampton W, Bollinger B, Hershfield HE, et al. Predicting advertising success beyond traditional measures: new insights from neurophysiological methods and market response modelling. Journal of Marketing Research. 2015; 52(4): 436-52.

13. Grabner DB, Huber M. The effect of neuromarketing elements at the pos on the consumer's decision making process in the retail sector. Journal of Business and Economics. 2016; 7(2): 276-83.

14. Boksem MAS, Smidts A. Brain responses to movietrailers predict individual preferences for movies and their population-wide commercial success. Journal of Marketing Research. 2015; 52(4): 482-92.

15. Chancellor B, Chatterjee A. Brain branding: when neuroscience and commerce collide. AJOB Neuroscience. 2011; 2(4): 18-27.

16. Hammou KA, Galib MH, Melloul J. The contributions of neuromarketing in marketing research. Journal of Management Research. 2013; 5(4): 20-33.

17. Hsu M, Yoon C. The neuroscience of consumer choice. Current Opinion in Behavioral Sciences. 2015; 7(5):116-21.

18. Wonglorsaichon P, Sathainrapabayut P. Brand perception \& brand equity of baby accessory products in working moms' perspective. International Review of Business Research Papers. 2008; 4(1):385-95.

19. Vlasceanu S. Neuromarketing and evaluation of cognitive and emotional responses of consumers to marketing stimuli. Procedia - Social and Behavioral Sciences. 2014; 127: 753-7.

20. Akbari M. An overview to neuromarketing and its application. Shefaye Khatam. 2013; 2(1): 75-84.

21. Bayan L, Fatemeh Alipour, Pirhossein Koulivand, Samaneh Sadat Dastgheib. Neuromarketing: the cognitive approaches to consumer behavior. Shefaye Khatam. 2014; 2(4): 46-59. 